\title{
Predation on a sacoglossan gastropod by a mushroom coral
}
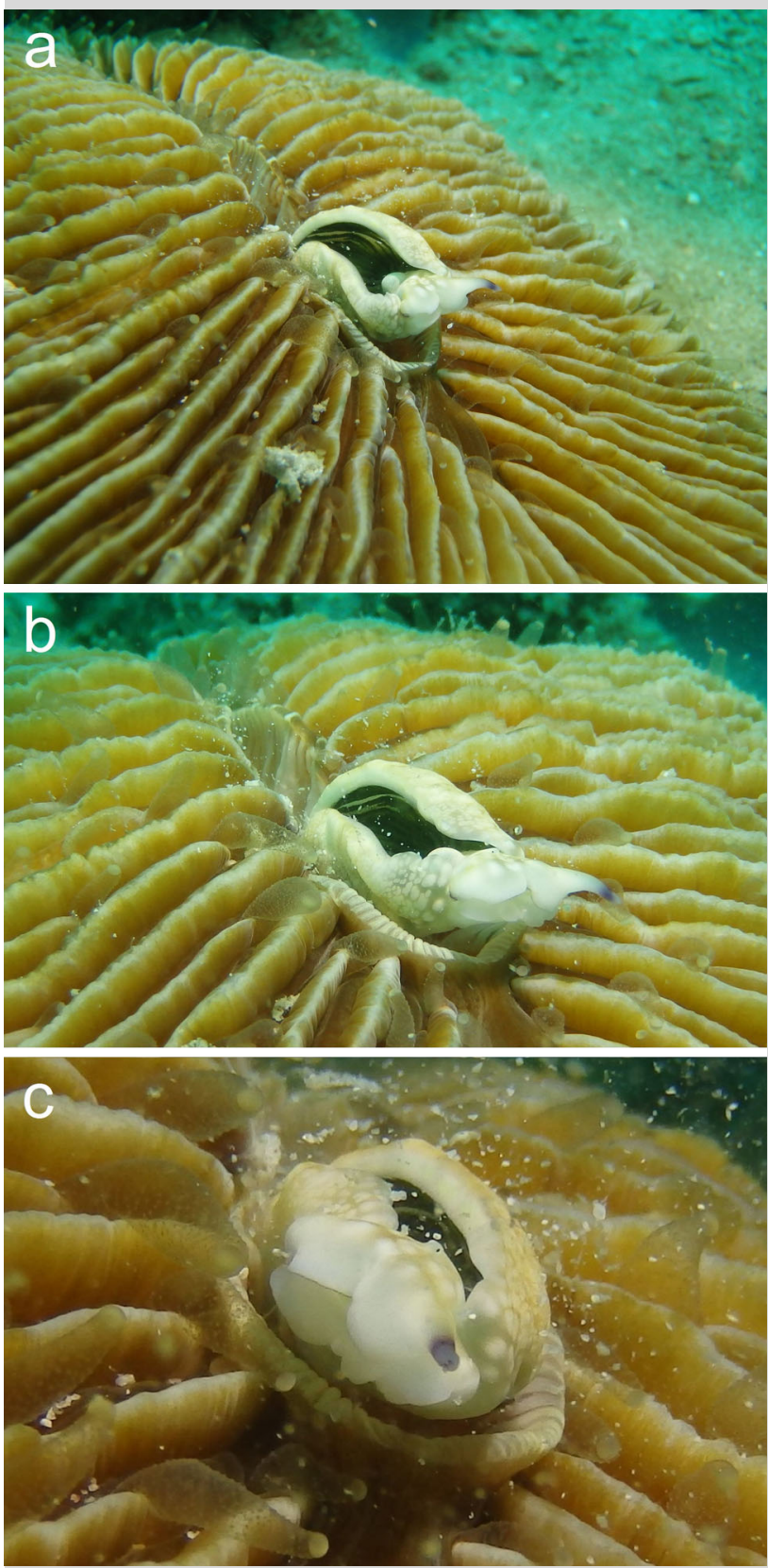

Fig. 1 Successive stages of a Pleuractis paumotensis coral ingesting a sacoglossan, Plakobranchus sp. (partially consumed; length $\sim 22 \mathrm{~mm}$ ), at Koh Tao, Gulf of Thailand. a Part of the coral's oral surface with the gastropod already inside the mouth (1322 hrs). b Mouth of coral becoming wider (1323 hrs). c The sea slug becoming swallowed (1324 hrs)
Only a few documented examples are known of predation on sacoglossans, which are heterobranch sea slugs famous for ingesting the cellular contents of algae (Krug et al. 2013). Known predators of sacoglossans include, for example, species of fish and crabs (Trowbridge 1994). Information on scleractinian corals eating large-sized prey became only recently available (Hoeksema and Waheed 2012); therefore, it is not surprising that no examples have been reported on sea slugs being eaten by corals.

During a field survey on a fringing reef off Sai Tong beach $\left(10^{\circ} 03^{\prime} 41^{\prime \prime} \mathrm{N}\right.$, $99^{\circ} 49^{\prime} 30^{\prime \prime} \mathrm{E}$ ) on December 22, 2014, at the island Koh Tao (Gulf of Thailand), a sacoglossan gastropod, Plakobranchus sp., was found being consumed by a monostomatous mushroom coral, Pleuractis paumotensis (Stutchbury, 1833) for $20 \mathrm{~min}$ (1320-1340 hrs). The coral was part of a mushroom coral assemblage on a sandy substrate ( $9 \mathrm{~m}$ depth) that is rarely visited by divers. The sea slug ( $22 \mathrm{~mm}$ long) was already inside the coral's mouth when it was discovered (Fig. 1). It is not known whether the individual was later expelled or consumption was completed but $<10 \mathrm{~mm}$ of its length remained by the end of observation with no signs of rejection.

The present specimen belongs to the $P$. ocellatus species complex, which is in need of further revision (Krug et al. 2013). Around Koh Tao, Plakobranchus slugs are commonly found year-round on shallow sandy substrates (0-20 m depth) where they are optimally exposed to sunlight. The unlucky individual had probably crawled against the coral's periphery, from where it was transported toward the mouth by the coral's tentacles (see Hoeksema and Waheed 2012). Incidental observations like this one can clarify the role of corals as predators, and which prey they can consume.

\section{References}

Hoeksema BW, Waheed Z (2012) It pays to have a big mouth: mushroom corals ingesting salps at Sabah, Malaysia. Mar Biodivers 42:297302

Krug P, Vendetti JE, Rodriguez AK, Retana JN, Hirano YM, Trowbridge CD (2013) Integrative species delimitation in photosynthetic sea slugs reveals twenty candidate species in three nominal taxa studied for drug discovery, plastid symbiosis or biological control. Mol Phylogenet Evol 69:1101-1119

Trowbridge CD (1994) Defensive responses and palatability of specialist herbivores: predation on NE Pacific ascoglossan gastropods. Mar Ecol Prog Ser 105:61-70

\section{R. Mehrotra ( $₫)$ C C. M. Scott · J. M. Rohrer}

New Heaven Reef Conservation Program, 48 Moo 3Koh Tao, Suratthani 84360, Thailand e-mail: rahul-m@ hotmail.co.uk

\section{B. W. Hoeksema}

Department of Marine Zoology, Naturalis Biodiversity Center, P.O. Box 9517, 2300 RA Leiden, The Netherlands 